\title{
Organizing bicycle traffic in Moscow to reduce air pollutant concentrations
}

\author{
Igor Pryadko ${ }^{1, *}$ \\ ${ }^{1}$ Moscow State University of Civil Engineering, 129337, 26 Yaroslavskoye sh., Moscow, Russia
}

\begin{abstract}
The objective of this article is to assess the prospects for development of cycling as a mode of transport in major cities in Russia and worldwide. Towards this end, the author addresses bicycle traffic organization patterns in the cities of Europe, South Eastern Asia and South America. The methods, employed in this research project, include sociological data collection, or the polling of urban residents (residents of the Russian capital), the retrospective analysis of sources, including news articles, the comparative historical method and forecasting. In the article, the impact produced on the urban environment, namely, on the surface layers of the urban atmosphere, by the motor traffic is compared with the one produced by the bicycle traffic. The mission of this research project is to analyze development of cycling network routes, parking lots, and accompanying small architectural forms in Moscow. The author employs methods of environmental monitoring to assess the impact produced by the motor transport on the environmental situation in the city. The conclusion is that there is a need to develop the urban walking infrastructure, to expand the urban cycling network, and to convert to the biosphere compatible urban transport.
\end{abstract}

\section{Introduction}

More often than not urban planners and architects face the challenge of limiting pollutant emissions caused by human economic activities and designing a clean and biosphere compatible urban space. This challenge is also to be met by executive urban authorities, responsible for organization and operation of urban transport networks. Transport needs are associated with such objectives as organization of an urban transportation system, road maintenance services, etc. Actions, taken by urban authorities to reduce hazardous pollutions into the atmosphere, are also relevant.

The willingness to reduce the environmental damage is converted into a project implemented by road maintenance authorities that plant trees and bushes along motor roads and highways, develop green areas and parks, while the construction of roads and highways takes account of climatic challenges typical for particular roadbuilding areas. However, these undoubtedly necessary actions cannot reverse the state of affairs. Supplementary efforts are to be invested both by urban residents and public transport operators. These efforts will be discussed in the article.

\footnotetext{
* Corresponding author: priadcko.igor2011@yandex.ru
} 
The mission of this work is to compare the efforts invested by municipal authorities and road maintenance services in European, South American, and Asian countries in order to limit motor traffic and to build cycle paths and pedestrian routes, with the state of affairs and desirable actions to be taken in the Russian capital and other Russian megalopolises.

\section{Literature overview}

The author employs the conclusions made by theorists and experts in urban transport planning and design, urban planners, and specialists in urban ecology. The author takes account of the conclusions made by contemporary researchers L. He, B. Agard, M. Trepanier [1]. Environmental consequences of the cycling network expansion are analyzed in the works written by Z.Y. Kou, X. Wang, S.F. Chiu [2], H.Y. Si, J.G. Shi, D.Z. Tang, G.D. Wu, J. Lan [3]. These authors analyze the actions taken to develop a comfortable architectural space, bicycle parking facilities, etc. Comparative analyses of the actions taken in particular Latin American and European megalopolises with a view to development of the social transportation infrastructure are performed by C.P. Bassani, B.M.A. Gomes and H.F. Pesseli [4], J. Larsen [5], and A. Paulsson [6]. These authors focus on the structure of urban transportation logistics, including cycling networks.

The works that generalize the international experience in developing transportation networks, focused on satisfying social and ecological needs of urban residents, are of particular importance [7].

\section{Materials and methods}

The author employs the polling method, the retrospective analysis of news messages (including those covering the finding of ecological monitoring actions launched in Moscow and the Moscow metropolitan area at regular intervals), as well as general research methods, including induction and deduction, modeling and forecasting.

Let's discuss the general methodological principles of this research project.

Contemporary science disciplines, arising at the interface of sociology and ecology, study the man-nature relationship. These disciplines respond to the question why the societal development and technological progress cause environmental crises. Present-day researchers believe that reduction in the biological diversity may endanger the sustainability of ecological systems, while humans, willing to boost production efficiency, intrude ino the basic regularities of ecological systems and their dynamic development. This research employs methods of social ecology; this discipline develops at the interface of sociology and ecology. In particular, issues of ecology are analyzed in the context of this approach in terms of their influence on the processes that are underway in the environment, while any human impacts are boosted by transformatory activities peroformed by humans. This approach also encompasses the attitude of the society and social groups to the condition of the environment, therefore, it contemplates methods used to collect sociological information. As it was mentioned above, a sociological poll, launched among student of several Moscow universities, serves as one of the methods employed in this research project. The random sampling method was used to identify 142 respondents, students of the Moscow universities. As the poll was launched among the students who proactively used public transport, the number of female respondents exceeded the one of male respondents (see Fig. 1). 

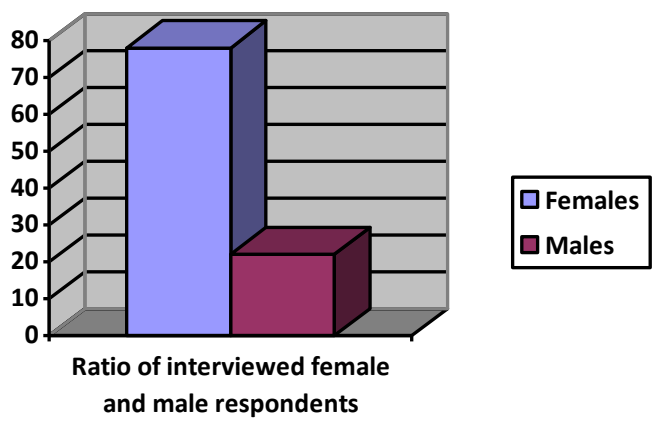

Fig. 1. Sociodemographic characteristics of the respondents.

The author employs forecasting methods. In this work, he analyzes the principles underlying the design and organization of urban transport networks that serve as the basis for designing post-industrial cities. Extension of pedestrian areas, decentralization of the urban space and making versatile urban services available at a walking distance are among the key trends. The redevelopment and potential turnover of industrial urban areas, which are already practiced in the capital, are also of primary importance. These actions produce an immediate impact on Moscow transport flows and its environmental situation. The author believes that the above principles are of primary importance for the spatial organization of urbanized areas.

\section{Results}

Moscow department of transport and road building has assumed the responsibility for the system of ecological transport in the Moscow metropolitan area. This institution is the policy maker in road building and traffic organization in the metropolitan agglomeration. The convergence of passengers and pedestrians, on the one hand, and owners of vehicles, on the other hand, is an important road building trend. Many cities and towns promote cycling transport as an alternative to pedestrianism and motor transport. Motor transport slows down due to urban traffic congestions; therefore, substitution of gasoline-powered vehicles by bicycles is a vital action.

Representatives of ecology movements make sweeping proposals to give up motor traffic. Environmental activists think it necessary to promote cycling in all kinds of ways, to extend cycle paths, to reduce the car fleet, and, therefore, to reduce the amount of pollutants emitted into the atmosphere. In the meantime, concentrations of pollutants go up year by year. Indeed, during rush hours, when the motor traffic slows down, surface layers of the atmosphere accumulate nitrogen oxide, carbon oxide, silicon oxide and other artificial pollutants. The concentration of volatile carbon is extremely high; its value may exceed acceptable values by $1.5-2$ thousand times. Numerous research articles cover the concentration of pollutants in the surface layers of the atmosphere in the capitals of China and Japan [8] [9] [10] [11]. The Russian capital does its best to catch up with the countries of the South Eastern Asia. In Moscow, motor transport accounts for 93\% of all pollutants that reach the surface layers of the atmosphere. This value reaches $86 \%$ in St.Petersburg. In absolute values, the amount of pollutants in the atmosphere of the Russian capital reaches one million tons a year, while in St.Petersburg it is half as much. Moreover, Moscow is the city that has radial transport routes. Therefore, the urbanized area of the Russian capital is insufficiently blown by air flows. As a result, in the centre of this megalopolis, the 
concentration of hazardous substances exceeds the one in the environs 30 -fold. The surface layers of the atmosphere in particular cities within the Moscow agglomeration accumulate highly hazardous substances as nitrogen dioxide, nitrogen oxide, phenol, and nitrogen chloride. They also contain suspended substances, the concentration of ammonia and industrial dust is high there. Development of cycling as a mode of transport may serve as the solution, however, presently, bicycle traffic in major Russian megalopolises is utterly problematic, and bicycle parking facilities are scarce.

Nonetheless, the environment of this megalopolis is bad for the health of cyclists, as well. Harmful substances find their way into human organisms through respiratory organs, therefore, $90 \%$ of all intoxications are associated with respiratory organs. Moreover, these organs are immediately exposed to the hazardous impact produced by the polluted urban atmosphere, as about $50 \%$ of admixtures whose particles have the radius of $.01-.1$ micron penetrate into lungs and stay there.

The particles that get inside human bodies have a poisonous effect, because:

1.their chemical composition and physical nature make them toxic (poisonous);

2.they hurdle the operation of mechanisms that clear the respiratory tract, which is particularly important for a cyclist whose gas exchange with the environment is more intensive than the one of a pedestrian;

3. Dust particles and pollutants serve as carriers of poisonous substances absorbed by human organism.

Pollutants produce a cumulative effect in the cities. In some cases, interaction between particular pollutants causes not only chain reactions, but also adverse affects, which are much more substantial than those produced by these substances in isolation. The impact intensity is also driven by the exposure duration.

The findings of the statistical analysis, employed by the author in this article, enable him to sufficiently accurately assess the transport situation for urban residents.

\section{Transportation system patterns: the global experience}

The slogan that reads as "a car free city" is proposed by environmental activists against the background of the ever polluted urban environment, deteriorating architectural solutions and intensive traffic. Some municipalities make resolute steps in pursuing these aims. Let's address the global experience.

Below we will analyze specific solutions for urban transportation problems and demonstrate optimal traffic organization patterns for megalopolises, and we will also analyze the measures aimed at reduction of hazardous pollutions emitted into the surface layers of the atmosphere. Experts offer three potential solutions for these problems. They are urban traffic restriction, public transport development, and setting transport priorities pursuant to the principle that reads as "from primary to secondary": "pedestrians - public transport - personal car."

The findings of our poll have proven that urban residents consider urban transport as the main source of pollutants emitted into the atmosphere. The majority of our respondents believe that hazardous emissions into the atmosphere are the reason for respiratory and cardiovascular diseases. I find it nearly impossible to contest this statement. The accumulation of nitrogen compounds in blood causes azotaemia. Blood thickens, and this process fosters thrombogenesis. $84.5 \%$ of our respondents are convinced that the polluted urban atmosphere is the reason for health problems experienced by urban residents. Mere $4.2 \%$ of our respondents gave a negative answer to this question, while $11.2 \%$ gave no answer. 


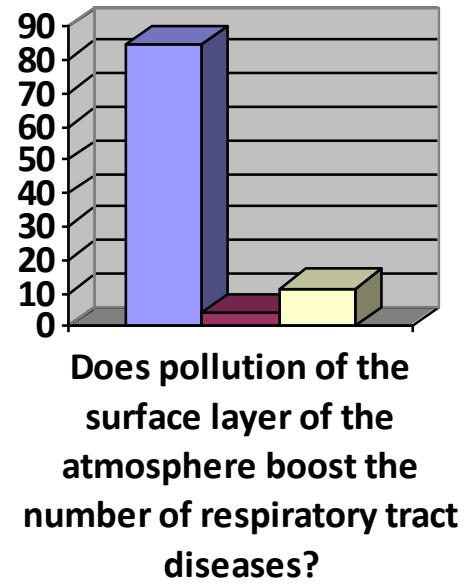

\begin{tabular}{|l|}
$\square$ yes \\
$\square$ no \\
$\square$ no answer
\end{tabular}

Fig. 2. The opinion expressed by the respondents in respect of the impact produced by polluted surface layers of the atmosphere onto the growth of respiratory and cardiovascular diseases.

Mere $13 \%$ of our respondents are ready to use public transport instead of their personal cars, while $9 \%$ of the respondents are ready to do it under certain circumstances. The majority of our respondents $(42 \%)$ are not ready to give up using their personal vehicles.

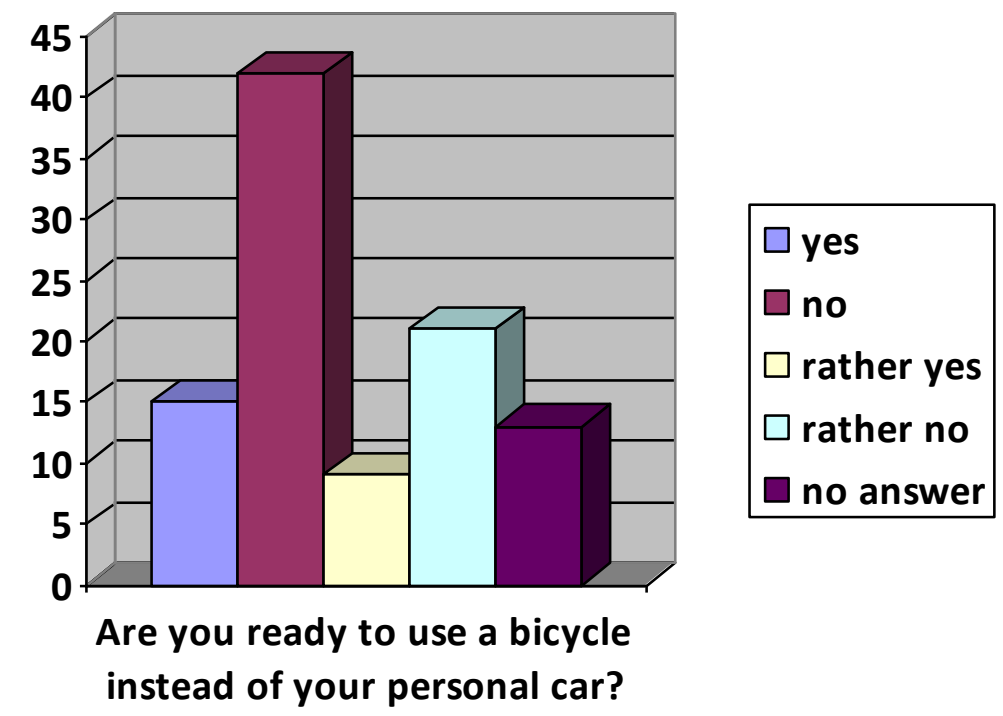

Fig. 3. The willingness of the respondents to use bicycles "for the sake of the environment."

Public transport routes and patterns, implemented in the European capitals, deserve our attention. The system of actions taken by the municipal authorities in the capital of Denmark, is particularly interesting. Copenhagen authorities have minimized the infrastructure for transport facilities and extended convenient pedestrian and cycling areas. These actions are supplemented by further development of the public transport network that is preferable in the Danish capital. Positive developments followed. Despite the fact that 
every second resident of Copenhagen owns a car, over fifty percent of urban residents use bicycles to travel around the city. The share of residents that travel around the city by cars, has plummeted to $24 \%$ [12]. It is assumed that the cycling transport development produces impact on communications between residents of the Danish capital [13]. In China, cycling remains the most widely spread mode of transport in megalopolises, particularly in Shanghai, Beijing and other major administrative centres. A bike sharing network is widely spread in Colorado, USA [14]. The experience accumulated by Brazil is also interesting. Here, a system of priorities applies to transport vehicles in Curitiba: "public transport is more important than motor cars; an automobile in motion takes priority over the one that is parked" [15]. The launch of the smart house system has contributed to the improvement of the ecological situation there [16]. As a result, the content of some hazardous pollutants in the air goes down [17], and the number of urban residents that fall sick with respiratory diseases reduces, as well [18].

However the majority of the municipalities, suffering from traffic problems, are not going to give up using motor vehicles, although the application of restrictions to their operation is understood as the main problem. For example, "in those districts where unlimited use of motor vehicles may cause substantial problems for the society and where motor transport use must be limited, effective alternatives were considered" [14]. All these actions helped the city to initiate performing its principal function: of transportation.

The traffic problem is the main challenge to be met by major megalopolises in China. This state is the leader in urban highway construction. In its turn, the road network of the Russian capital grows at a fast pace; according to several expert polls, it has caught up with the pace of the road building construction in Beijing, the capital of the People's Republic of China. However the growth of the number of motor vehicles, registered in the Russian capital, demonstrates the same rate. In April 2018, the State Traffic Safety Inspectorate provided information about the number of motor cars registered in the Moscow metropolitan area. At the time, it reached 8.3 million, and the average annual growth rate was assessed at 300 thousand vehicles. Back in 1991, one thousand residents of the capital owned 110 cars, and in 2018, the number of cars exceeded 370 per one thousand of residents.

Traffic is recognized as a substantial problem in the Russian capital. Unfortunately, such measures as the arrangement of dedicated public transport lanes, the widening of old highways and the construction of new ones, which are offered as the solution, cannot reverse the situation. In the UK, in the 90 ies of the $20^{\text {th }}$ century, a movement was founded by D. Jordan. Its mission was to limit the number of cars in the streets of the British capital. Jordan and his allies organized street protests, performances and public rallies. However street protests and disobedience campaigns are far from being the appropriate solution for the Russian capital.

\section{Actions taken by the Moscow authorities to organize transport in the capital}

Let's analyze the Moscow transportation system and its most recent changes. Media agencies make the point that over the last two years Moscow residents used bicycles more and more frequently. According to the information provided by the Moscow rent-a-bike services, since April 2019, over 4 million bike trips have been made, and this figure exceeds the one of April 2018, when 2.4 million cyclers rented bikes. According to M. Liskutov, Director, Moscow Department of transport and road building, rent-a-bike services have turned much more popular. The number of bike trips is expected to exceed 3 million by the end of the coming season. 
According to Price Waterhouse Coopers (PwC), "unlike Beijing and the majority of other cities [...], over the last five years Moscow sustainably increased the number of new roads built and commissioned in the city." When assessing the efforts fostered by the Moscow authorities over the last eight years, Moscow media report on 8.201 kilometers of roads and 254 bridges commissioned during this period. This effort accounts for $19 \%$ of the overall road urban network that used to be in operation there. Indeed, the traffic of public and personal vehicles has also gone up. At the same time, the number of cycle paths goes up, as well. Their number is particularly impressive in the Moscow parks and forests, located in the south west of the megalopolis.

\section{Cycling promotion: the experience of Moscow}

The development of rent-a-bike services and cycle paths is limited. Actions launched to promote a healthy lifestyle and to develop an ecological urban environment generate awareness of cycling as a sport. These actions include the international "Cycling night", held both in the Russian capital and in other megalopolises worldwide. In 2019, this action was held on June 29 in Moscow. The primary mission of this event is to promote cycling as a mode of transport, and its secondary mission is to demonstrate the beauty of Moscow streets and yards both to urban residents and tourists. Installations were arranged in Moscow streets, electronic presentations were delivered, city tours were organized and short lectures were read on the eve of the event to generate awareness about the most prominent Moscow buildings and structures. Later we will address art as a vehicle for the promotion of environmental protection.

So called "pit stops" are arranged along the route. Their mission is to help participants to learn more about the history of Moscow streets and squares. Short lectures will also be delivered at "pit stop" areas. They will unveil the so called "Moscow mysteries" and "urban legends" and they will turn the event more captivating and attract the young audience. Some lecturers will speak about the Moscow architecture and urban planning. Lectures on "ghost houses", or the architectural projects that remain undelivered, will also be presented during Cycling nights. The Palace of Councils is a true highlight of the Cycling nights programme: this project initiated a drastic restructuring in the Moscow of the 30ies, when new highways were constructed and houses built to emphasize this tremendous structure. Some lectures covered the development of cycling in the $20 \mathrm{ies}$ and $30 \mathrm{ies}$ of the $20^{\text {th }}$ century. It is important that cycling promotion events are organized and held on the regular basis.

In 2019, the Russian capital hosted the $12^{\text {th }}$ Moscow International Cycling Night. The event appealed not only to cyclers, but also to pedestrians willing to learn more about cycling and its scope of problems. The majority of participants included families of sportsmen, including their children. Therefore, major events of the Cycling Night commenced at 8:00 pm, instead of 10:00 pm, as it had been originally planned. Schoolchildren and students were allowed to bring their personal skateboards and scooters. Organizers welcomed any creativity to be manifested at numerous fest events.

Those participants, who brought their personal scooters, stake boards, or bicycles, received personal repair kits to safely reach the finish line. Amateur sportsmen got an excellent opportunity to prepare their vehicles for a trip at the self-service bicycle repair shop which was in operation during the event. In summer, on the eve of the sports forum, the self-service bicycle repair shop was opened and operated in the test mode. Even today it welcomes customers who can use the services of a professional repairman or rent particular repair instruments, some of which are really costly. 


\section{Cycle paths built in the parks for the residents of New Moscow}

Moscow has been building numerous parks and public gardens that accommodate sports facilities, sports sites, courts, stadiums, let alone bike paths and parking lots. The Gloria Park project, implemented not far from the Ulianov forest, focuses on the promotion of cycling. The project features a combination of the two park styles, including ecological minimalism and ethnic style. On top of cycle paths and the sports infrastructure, the park has an open-air theatre and multi-purpose sports sites designated for children and adults. Amusement rides are already in operation; they occupy the area of five thousand square meters. The park also has several rent-a-bike centers. Cycle paths are to be built within the framework of a different project, that is, the Park of Heroes located close to Kuzovlevo village. A network of cycle paths was designed as part of the project developed by the architects employed with limited liability company SPiCH and NP Research Institute of Transport and Road Facilities for Kuzminki district in Moscow. The bank line and the crinkle of the Moskva river are being repaired. The embankments, which are being built there, can also serve as cycle paths. Embankment repair works are to be completed in 2023. Nonetheless, through the eyes of Muskovites, a bicycle can never become an alternative to a motor vehicle, rather, cycling is a popular sport that is often associated with extreme sports, which can only be practiced in the summertime. An author of a publication in a popular newspaper circulating in New Moscow said: «A hot summer is still wandering about the city, it wheels around and works the pedals there; extreme sports lovers don't stay in: they seize the day and try to clear new heights.») And that's what they really do!

\section{Discussion}

Having discussed the result of the analysis, performed by the author, one can make a conclusion that cycling and its development is one of the most ambitious trends in the urban transport system. However, the very first steps have just been made so far. The network of cycle paths and rent-a-bike offices is being developed, and the latter do not have enough bicycles for each potential cyclist, willing to rent a two-wheeled vehicle. Moreover, the effective legislation does not offer enough protection for the cyclist's rights, it lacks provisions aimed at prevention of road traffic accidents. The car fleet is a lot stronger and more numerous than any alternative modes of transport. No conditions needed to motivate car drivers to use public transport or ride their bicycles are available today.

This statement is proven by the findings of our poll. Mere $1 \%$ of our respondents use bicycles to get to their universities, $3 \%$ move around the city on foot or by bicycle. $59.2 \%$ of the polled students use public transport and 5.6\% drive their own cars, as far as gasengine vehicles are concerned. Besides, a substantial portion of our respondents are convinced that the condition of our environment can only be improved, if major highways are moved out of the city. However, students have no idea how the transport network will function in this case ( $73 \%$ gave no answer to this question).

The situation may only be improved if several factors are taken account of. One of them is the cycling technique. Useful information must be distributed among cyclists; cyclists must ride their bicycles safely. It is noteworthy that the "Cycling Night" hosted another event, it was the official opening of the Cycling School in the museum of Moscow. Its programme had free master classes, a short-distance cycling contest, and the "Fast Carbohydrates" project (which is particularly good for those who spend long days at the wheel, even if it is the wheel of a bicycle).

Poor knowledge of the traffic rules is another problem. The new Cycling School, founded in the Museum of Moscow, is to fill this gap. In his interview, one of the Cycling School organizers said that "cycling develops proactively in Moscow." Public activists 
make a point that cyclists (children and teenagers) ride along oncoming lanes and ignore red traffic lights, they fail to turn on the lights in the darkness and never wear helmets. Therefore, the mission of the events, described in this work, is to enlighten cyclists. Special courses, launched at the Cycling School, will help cyclists to choose bicycle models, optimal travel routes and use safe bike riding techniques.

The author believes that these awareness generation efforts will make cycling more popular and safer.

\section{Conclusions}

The author analyzes measures and actions launched to reduce emissions of pollutants into the surface layers of the urban atmosphere. The author also analyzes the measures to extend green areas and promote urban cycling. The author has also assessed the prospects for cycling promotion and development in major megalopolises in Russia and worldwide. Moreover, the author has studied cycling traffic patterns in the cities and towns of Europe, South Eastern Asia and South America. The growing number of urban vehicles reduces environmental safety, if it remains uncontrolled. Both the natural environment and human health, including the one of cyclists, are at risk. The author believes that the best practices of Denmark (Copenhagen), China and Brazil (Cutriba) must be adopted in the largest Russian cities.

Therefore, promotion of cycling is of vital importance; it may be performed at international events launched in the Russian capital. In the course of the research project, the author studied the best practice in designing cycle paths, bicycle parking lots and small architectural forms in Moscow. He also demonstrated the difficulties that accompany this process. In particular cases, cycling promotion is reduced to pompous promotional events, while practical steps are only taken in limited directions. A lot is yet to be done to organize cycling traffic in the capital of the Russian Federation and to develop a truly barrier free environment in the Moscow metropolitan area.

\section{References}

1. L. He, B. Agard, M. Trepanier, Transportmetrica a Transport Science, 16(1), 56-75 (2020). DOI: 10.1080/23249935.2018.1479722

2. Z. Y. Kou, X. Wang, SF. Chiu, H. Cai, Resources Conservation and Recycling, 153, 104534 (2020). DOI: 10.1016/j.resconrec.2019.104534

3. H. Y. Si, J.G. Shi, D.Z. Tang, G.D. Wu, J. Lan, Resources conservation and Recycling, 152, UNSP 104513 (2020). DOI: 10.1016/j.resconrec.2019.104513

4. C. P. Bassani, B.M.A. Gomes, H.F. Pessali, Rosa dos Ventos Turismo e Hospitalidade, 12(1), 154-168. DOI: 10.18226/21789061.v12i1p154

5. J. Larsen, Mobilities, 12(1), 53-75 (2017). DOI: 10.1080/17450101.2014.993534

6. A. Paulsson, Urban Studies, UNSP 0042098019895231 (2020). DOI: $10.1177 / 0042098019895231$

7. X. Chen, Z. Yuan, Journal of Cleaner Production, 249, 119397. DOI: 10.1016/j.jclepro.2019.119397

8. S.W. Liu, X. Tian, Y.L. Xiong, Y. Zhang, H. Tanikawa, Journal of Cleaner Production, 247, 119083 (2020). DOI: 10.1016/j.jclepro.2019.119083

9. Q. Lv, H.B. Liu, J.T. Wang, H. Liu, Y. Shang, Science of the Total Environment, 703, 134394 (2020). DOI: 10.1016/j.scitotenv.2019.134394 
10. H. Shiraki, K. Matsumoto, Y. Shigetomi, T. Ehara, Y. Ochi, Y. Ogawa, Applied Energy, 259, UNSP 114196 (2019). DOI: 10.1016/j.apenergy.2019.114196

11. Y.J. Pan, F.X. Qiao, K. Tang, S.Y. Chen, S.V. Ukkusuri, Science of the Total Environment, 703, 135533. DOI: 10.1016/j.scitotenv.2019.135533

12. H. Skov-Petersen, B. Barkow, T. Lundhede, J.B. Jacobsen, International of Geographical Information Science, 32(7), 1469-1484 (2018). DOI: 10.1080/13658816.2018.1436713

13. E. D. Wilhoit, Western Journal of Communication, 82(2), 217-237 (2018). DOI: 10.1080/10570314.2017.1306098

14. D. Dreier, S. Silveira, D. Khatiwada, K.V.O. Fonseca, R. Nieweglowski ,R. Schepanski, Transporation, 46(6), 2195-2242 (2019). DOI: 10.1007/s11116-018-99250

15. Y. J. Hu, Y. P. Zhang, D. Lamb, M. M. Zhang, P. Jia, Applied Energy. 247, 1-12 (2019). DOI: 10.1016/j.apenergy.2019.04.007

16. A. Hojda, T.M.D. Fariniuk, M.D.B. Simao, Economia Sociedad y Territorio. 19(60), 79-108 (2019). DOI: 10.22136/est20191298

17. E. Felix, L. Gidhagen, M. F. Alonso, E. P. Nahirny, B. L. Alves, D. Segersson, J. H. Amorim, Air Quality Atmosphere and Health, 12(7), 837-846 (2019). DOI: 10.1007/s11869-019-00701-z

18. F. T. de Souza, Journal of Urban Health, 96(4), 591-604 (2019). DOI: 10.1007/s11524018-0271-5 